\title{
Coaching and Ethical Leadership: A Competence Executive Coaching Model for the Development of Ethical Leadership
}

\author{
Lurdes Neves \\ University of Oporto, Portugal
}

\begin{abstract}
The current transformations in societies and work contexts are putting managers in ambiguous situations and with consequent impact on the leadership profile when trying to adapt to those changes. It is in this context that the executive coaching models and coaching programs that aim to help leaders develop new attitudes and skills and to achieve organizational goals arise. Empirical research on executive coaching, however, has lagged far behind, and theoretical work on the processes underlying effective coaching has been limited. Consequently, the purpose of this work is to plan a competence executive coaching model for ethical leadership based on a literature review. It also provides a conceptual framework for intervention on ethical leadership. Based on the literature review of Neves, Jordão, and Cunha (2013a), there are no results that relate the model development and executive coaching construct of ethical leadership. Therefore, we aimed to draft a model of executive coaching for the development of ethical leadership. The proposed model is based on the results presented in the literature review of Neves, Jordão and Cunha (2013b) and integrates both the theoretical model of ethical leadership Hoog and Hartog (2008) and the perspective of Berling, Weber, and Kelloway (1996). This model is important to support the planning and implementation of executive coaching in ethical leadership development.
\end{abstract}

Keywords: executive coaching, executive coaching models, ethical leadership

\section{Introduction}

Societies are currently going through large structural changes, being involved in a process of economic, political, and technological globalization that affects organizational strategies and firms' decision-making.

With the increasing of organizational competitiveness, coaching is becoming more and more necessary, since the success of organizations is strongly dependent on the knowledge and learning processes of their employees. The growing popularity of coaching is visible in all sectors of activity and follows the increasing spread of consulting and inter-company training. Over the last decade, coaching has also become one of the top five strategies for the development of leadership and change to face the continuing challenges in organizations (Bennett \& Bush, 2009). Coaching main purpose is to achieve excellence in results, not only at a personal level but also organizational. That is possible through the effective use of the potential and real capabilities an individual has, thereby allowing a development of its knowledge and experience.

The coaching process should be developed on an individual, intentional and planned basis, and the identification of the particularities of each element submitted to coaching is essential, so that everything is in accordance with the environment and functions performed and it is possible to disseminate the process through

Lurdes Neves, Ph.D., professor, Faculty of Psychology and Educational Sciences, University of Oporto. 
all the organization or each working team.

Coaching is not about learning "what" but rather learning "how", which is becoming increasingly relevant in the individual and therefore organizational effectiveness. It is not enough to have the right information, you need to know how to implement it and that necessarily goes through those who have the skill and competence for such (Hale \& Whitlam, 2000).

Coaching is a short-term relationship between a coach and a client that provides feedback about the areas that require change (Milner \& Bossers, 2004). Coaching is a one-to-one trust relationship that aims to foment personal and professional learning and stimulate growth, in which the relation is intended to give a boost to "professional advancement", in other words, a significant change that potentiates individual development (Haynor, 1994; Price, 2009).

The present work refers specifically to executive coaching that emerges from the application of coaching to the organizational leadership and constitutes one of the methodologies that can contribute the most for the development of psychological variables in the professional performance. From the several areas of intervention of executive coaching, we refer in the present work to the application of executive coaching to development of ethical leadership behavior in organizational context.

We expect that coaching contributes positively to the development of ethical leadership behavior (Berling, Weber, \& Kelloway, 1996) and that may be useful for the development of leadership behavior, seeing the success they have been evidencing in the transformation of leaders and transformational leadership behavior (Berling et al., 1996). Therefore, the aim of this paper is to propose a model of executive coaching to the development of ethical leadership.

\section{Executive Coaching Definition}

In the review of the literature on executive coaching, we can see different perspectives about the concept. Some have defined the role of executive coaching limiting it to the individual level (Kampa-Kokesch \& Anderson, 2001). In contrast, other authors prefer a broader definition, extending it to the organizational level (Bacon \& Spear, 2003; Kilburg, 2000, 2004). Although most authors define coaching as a one-to-one relationship, between a professional coach and an executive (coachee) (Whitmore, 2002, p. 468) with the aim to provide behavioral change through the coachee's self awareness and learning, and thereby achieving individual and organizational success, Joo (2005) highlighted coaching in groups as the preferred tool for behavior change. According to Bennet's review (2010), the definitions of executive coaching tend to group around learning and development of performance, with the intent of facilitating change and personal growth. Executive coaching may contribute to help leaders develop new attitudes and competences in order to achieve organizational goals necessary to adapt to organizational changes.

The principle of executive coaching is to provide learning, behavioral change and growth of the coachee for the economic benefit of the client who uses it. Despite the differences, the objective translates into behavior change, self-knowledge, learning, and finally, career and organizational performance success (Sherman \& Freas, 2004).

In this paper, we adopt the concept of executive coaching as a learning process with a practical guidance focused on specific activities, directly linked to the functions performed by the client, which meets the design of Cunha, Marcelino, Oliveira, and Rêgo (2007) who consider it as a planned and continuous improvement process and with personal and professional fulfillment, especially based on action learning and maieutics. 
Considering coaching models presented in the literature, it also possible to enunciate a variety of approaches, as referenced in the literature review of Neves, Jordão, and Cunha (2014a).

Now, we will define leadership and, integrated in this concept, we will develop the ethical leadership construct.

\section{The Concept of Leadership}

The reviewing of the literature allows referring a variety of classifications and theoretical models about the concept of leadership.

For this work one of the most important dimension of leadership is to consider it as an influence relationship, conducted with leaders and followers, seeking real change in the organization, taking into account that they have to reflect the mutual purposes of leaders and followers, so, lead means to influence, guide and direct and know what is necessary to make (Bennis \& Nanus, 1985).

Leadership is related with the way change is deal with and its relevance comes mainly from competitiveness and volatility of the current business world (Kotter \& Heskett, 1992).

In this work, is adopted the definition of Sampaio (2004), who considers leadership as an interpersonal factor of influence that appears as a power to transform knowledge into action, resulting in a desired rate of performance. According to the author, leadership is seen as a personal quality, that is, as a set of personality trait that makes an individual a leader, according to the characteristics of the situation in which the individual is and also as a social phenomenon that occurs only in social groups. So, the leadership style adopted may give the organization the needed flexibility to achieve its goals, in a hostile indoor and outdoor environment constantly changing.

Referring to the literature, the other important dimension of leadership is related with the leader's abiliy to learn and develop with training. It is possible to see that there are several theories explaining the concept of leadership and it stands out the self-directed learning theory of Boyatzis (2007) which is based on the assumption that the leader can develop or purposely reinforce a quality which is already there, a quality that is needed, or both. This requires the leader to develop a clear vision of the ideal self and a true vision of the real self. This learning process is more efficient and long-lasting if the change process is being understood while it is running.

The purpose is to use each of these findings, which may happen during the coaching process as a tool to make the changes that are needed in the leadership profile. The leader can make the following findings regarding the self-awareness of its leadership profile:

(1) The ideal self-How do I want to be?-This first discovery leads to the vision of the ideal that we want as a model for ourselves, where we feel motivated to develop leadership skills;

(2) The real self-How am I? What are my strengths and my flaws? - It is like looking into a mirror and discovering how we are in fact, some of these facets are consistent with the ideal self, and then can be considered as strengths;

(3) The learning program - enhance the strengths and reduce the flaws-devising a plan for the improvement of our capabilities;

(4) Try the new behaviors, thoughts and feelings, until completely dominate them-comes from the practice of the new leadership skills;

(5) Develop trusting relationships that support change and make it possible-This discovery can occur in 
any of the various stages of the process and consists in realizing that we need others to be able to identify our ideal self and our real self, to discover our strengths and our flaws and to be able to experience and practice.

Therefore, leadership is an interactive process that results in the development of new habits that come from the learning done and their integration in the structure of the individual personality. Ideally, this progression occurs through moments of discontinuity that give a new awareness and convey a sense of urgency. Other forms of training and education, such as coaching, may be useful in the transformation of leaders (Berling, Weber \& Kelloway, 1996), so executive coaching models may be in this case an important mechanism for changing the leader.

\section{Ethical and Unethical Leadership}

As a result of the many organizational changes that we are currently living, leaders are influenced by situations of uncertainty that may lessen their ability to lead ethically.

Integrated into the concept of leadership, ethical leadership is little explored in the field of organizations and management (Brown \& Treviño, 2006).

In recent years, has being grown the interest about the development and promotion of ethical leadership in organizations, given the impact that leaders can have on the conduct of the organization, its members, and organizational performance (as cited in Aronson, 2001; Kanungo, 2001; Trevino, Brown, \& Hartman, 2003), and even given the high cost of ethical lapses on their part.

For these reasons, we consider relevant the possibility of development of ethical leadership profile (operationalized in terms of the skills of morality and fairness, role clarification, and power sharing) through the implementation of the methodology of executive coaching for the achievement of organizational goals necessary to adapt to organizational changes, and designed a proposal of an executive coaching model for the development of ethical leadership.

Ethical leadership can be considered as "the demonstration of normatively appropriate conduct through personal actions and interpersonal relationships, as well as the promotion of such conduct to followers through two-way communication, reinforcement, and decision making” (Brown, Treviño, \& Harrison, 2005, p. 120), and thus refer to a moral person (characterized by traits such as honesty and integrity) and to a moral manager (create and diffuse a strong ethical message).

Based on the definition and in earlier investigations (e.g., Trevino et al., 2003), Brown et al. (2005) describe ethical leaders as honest, reliable, fair and supportive, able to make righteous choices and structure just work environments.

The research on ethical leadership has been considering how leaders should behave, contrary to how they behave in practice (Brown et al., 2005; Clegg, Carter, Kornberger, Messner, \& Laske, 2007; Clegg, Rhodes, \& Kornberger, 2007). Research on ethics in leadership has also been focusing on the characteristics of ethical and unethical leaders, emphasizing the personal dispositions of ethical leaders and contextual factors, namely the organizational culture, that promote ethical or unethical behaviors. The result of these guidelines is a dual vision of ethical leadership: (1) A positive perspective, focused on ethical leaders and organizations, so openly normative (that is, focused on what leaders should do); and (2) A pessimistic analysis that considers the cases in which ethics are ignored by leaders and their followers, based on cases of organizational misbehavior (Ackroyd \& Thompson, 1999). Both approaches are based on retrospective analysis and case studies, mainly with public impact. 
Leaders influence their organizations, even in the ethical dimension, through the modeling of roles, but are also influenced by their expectations, interpretations, and interactions with others, including their own followers (Glynn \& Jamerson, 2006; Kellerman, 2004). They are often involved in different ethical contexts, which makes it difficult for the "good" people "to make good decisions in bad situations" (Glynn \& Jamerson, 2006, p. 154). Kellerman (2004) also emphasized this fact, suggesting that poor leadership (including unethical leadership) is the result of the interaction of three factors: leaders, followers, and context.

In contrast with these components of the ethical behavior of the leader, Aronson (2001) describes the despotic leadership as being based on personal domination and authoritarian behavior centered in the interests of the leader and the exploitation of others. Other forms of unethical leadership that have received attention in the literature include abusive supervision and personalized charismatic or pseudo-transformational leadership (see Ashforth, 1994; Bass \& Steidlmeier, 1999; Beu \& Buckley, 2004; Bies, 2000; Howell, 1988; Tepper, 2000).

Based on this concept of ethical leadership, this study aims to propose an executive coaching model which enables the development of ethical leadership behaviors (operationalized in terms of morality and fairness, role clarification, and power sharing), contrary to an unethical leadership behavior (despotic leadership). Following the model proposed by Hoog and Hartog (2008), we expect that the behavior of ethical leadership contributes to the development of a positive relation with the performance of top management and optimism of the followers about the future. In contrast, we expect the behavior of despotic leadership to be negatively related with optimism of the followers about the future of the organization and with the performance of top management.

According with this perspective of Berling et al. (1996), other forms of training and education, such as coaching, may be useful for the development of leadership behavior, seeing the success they have been evidencing in the transformation of leaders and transformational leadership behavior (Berling et al., 1996). So, it is expected that coaching contributes positively to the development of ethical leadership behavior. The following figure shows the relationships proposed.

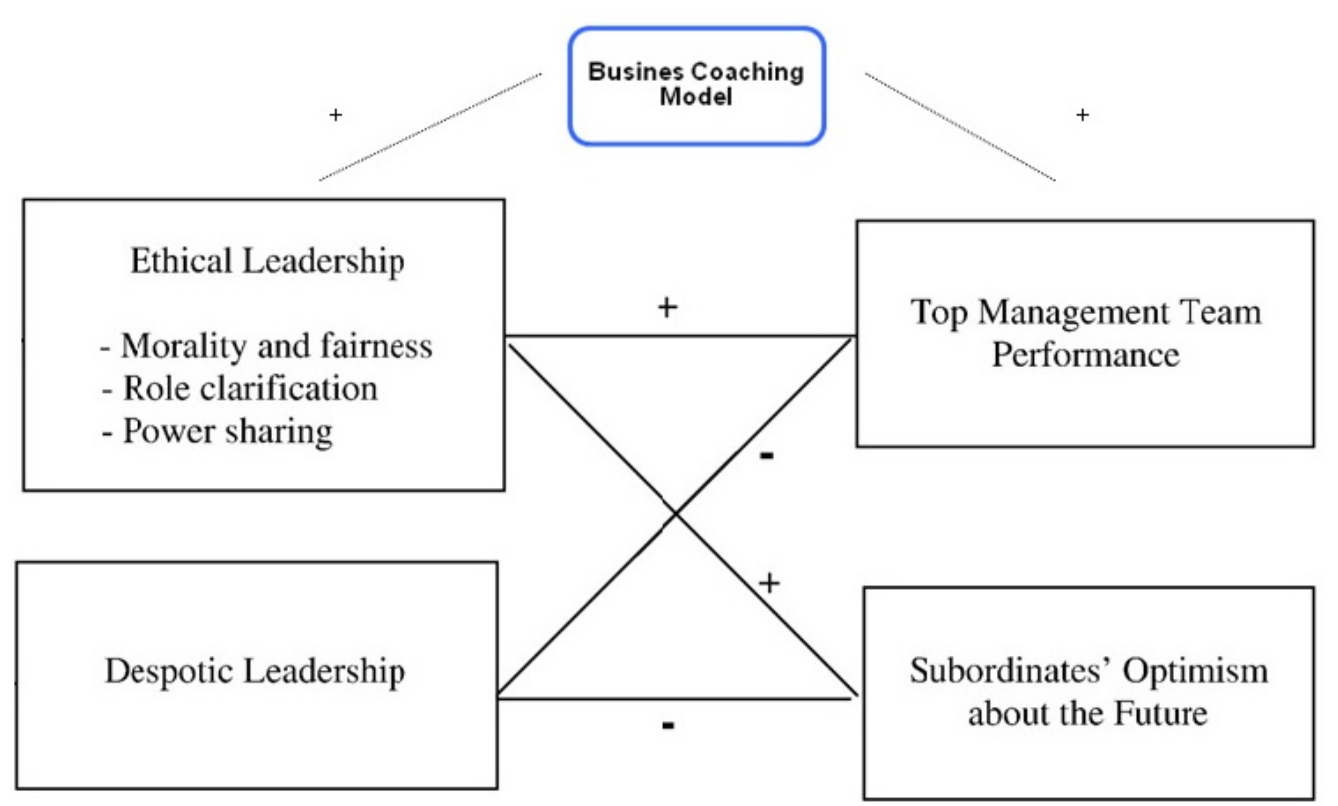

Figure 1. Adaptation of the theoretical model of ethical leadership by Hoog, Hartog, and Deane (2008) and the perspective of Berling et al. (1996) and on the Hale and Whitlam (2000) model. 


\section{Methodology}

The common patterns identified in models of executive coaching reported by Neves et al. (2013b) as well as the premises of the theoretical model of ethical leadership de Hoog and Hartog (2008) allowed to propose an executive coaching model for the development of ethical leadership according to the following steps: (1) building the relationship between coach and client; (2) problem definition/areas of development and the goal of the coaching process; (3) setting plans and goals for action; and (4) results and effectiveness of the implementation of coaching models.

After literature review by Neves et al. (2014a; 2014b), a search was also performed using the keywords: coaching, AND model (OR theory OR Framework), AND leadership, AND ethical leadership for the period 1990-2012, for which no results were obtained. The full text databases included Business Source Complete, Academic Search Complete, Educational Research Complete, MEDLINE, PsycArticles, PsychINFO and Academica, Psybooks and Psychology, and Behavioral Sciences Collection.

According to Hoog and Hartog (2008) the dimensions of ethical leadership considered (morality and fairness, role clarification, and power sharing) are measured by three subscales adapted to the Portuguese population (with adaptation and validation study of a Scale of Ethical Leadership to Portuguese Population by Neves et al., 2014a; 2014b) from the MCLQ (Multi-Cultural Leader behavior Questionnaire) (Hanges \& Dickson, 2004), with items with a response scale of seven points, ranging from 1 ("Strongly disagree") to 7 ("Strongly agree").

The dimension of morality and justice is measured by six items that assess the demonstration of honesty, reliability and high ethical standards, as well as the most understanding and fair treatment to subordinates, by the leaders.

The dimension of the role clarification is measured using five items that assess the transparency of the leaders, the commitment to open communication, clarifying the expectations and responsibilities.

The dimension of power sharing is measured by six items that assess behaviors that give voice to subordinates and allow them to participate in decision-making.

The despotic leadership is measured using a scale adapted from MCLQ (Hanges \& Dickson, 2004), which consists of six items that reflect the authoritarian behavior that serves the leader's own interests, overestimation of himself, insensitivity and exploitation of others.

Next, it will be presented the Executive Coaching model proposed for the development of ethical leadership behavior that was based on literature review of Neves et al. (2014a; 2014b).

\section{Results (Proposed Coaching Model) and Discussion}

Following the literature review presented by Neves et al. (2014a; 2014b), there were not found results that relate executive coaching models and the concept of ethical leadership and therefore describe the development of executive coaching models applied to ethical leadership behavior.

For this reason, the model of executive coaching for ethical leadership behavior's development is based on commonly accepted steps considered in the literature review of Neves et al. (2014a; 2014b) about the executive coaching models. The proposed model consists in seven stages of integrative development acting jointly and continuously, integrating in the central position a monitoring stage, referred as the Monitoring Stage of the model.

This model presents the main stages' components of executive coaching model for ethical leadership 
behavior development and it is important to define the conceptual framework to support planning and implementation of processes of executive coaching for the development of ethical leadership.

The presented model can be adapted to the context and needs of the organization and to the client and take into account the premises mentioned from the adaptation of the theoretical Model of ethical leadership by Hoog and Hartog (2008) and from the perspective of Berling et al. (1996) and the following premises based the literature review of Neves et al. (2014a; 2014b).

\section{Premises From the Proposed Executive Coaching Model}

Building the relationship between coach and client. The proposed model relies on building a relationship based on trust and open communication and in a non-judgmental environment that allows emotional support needed to develop a process of effective coaching (Giglio, Diamante, \& Urban, 1998; Hoojiberg \& Lane, 2009; Joo, 2005; Kowalski \& Casper, 2007; McNally \& Lukens, 2006; Passmore, 2007; Sherman \& Freas, 2004; Truijen \& Woerkom, 2008). At the core of the relationship, there must be a satisfactory level of confidence so that the degree of client involvement is boosted. The development of knowledge about the responsibilities, decision-making capabilities, and the client's status within the organization can also contribute positively to the construction of the relationship (Giglio et al., 1998, Keil et al., 1996; Kowalski \& Casper, 2007; McNally \& Lukens, 2006).

Problem definition/areas of development and definition of the goal of the coaching process. This model provides the inclusion of diagnostic tools to obtain feedback about the performance and the stage of development of the client to help to identify the strengths and weaknesses, motivations, expectations, and strategies for conflict resolution (Hoojiberg \& Lane, 2009; Joo, 2005; Keil et al., 1996; McNally \& Luken, 2006; Saporito, 1996; Sherman \& Freas, 2004).

In the diagnostic phase is also included the evaluation of the perception of peers, of top management and employees in relation to the client, through the application of tools such as the 360-degree assessment (Saporito, 1996; Sherman \& Freas, 2004), questionnaires (Hoojiberg \& Lane, 2009) or interviews (Keil et al., 1996). For setting the goal that has to be worked in the coaching process, other methods of questioning may also be adopted, such as evaluation of the areas of development which need to be worked via the coaching process, instead of more formatted assessment tools (Giglio et al., 1998; Passmore, 2007; Truijen \& Woerkom, 2008). According to the psychodynamic approach by Passmore (2007), it is relevant that the method of questioning adopts the use of open questions that promote self-awareness and questioning of automatic and intrusive thoughts (Passmore, 2007).

The client is responsible to identify the areas of development that should be targeted for reflection with the help of the coach (Kowalski \& Casper, 2007) and based on the interpretation of the feedback with the coach (Giglio et al., 1998; Keil et al., 1996; Sherman \& Freas, 2004) of the data obtained from the client, the feedback from the coach, from peers, superiors or subordinates (as described above).

It is also relevant the need of involvement and participation of top management in the adaptation of the definition of the goals to the needs of the organization and to the organizational culture (Giglio et al., 1998; Keil et al., 1996; Saporito, 1996). Top management may also determine the focus and priorities in setting goals so that the definition of objectives is a client's responsibility (McNally \& Lukens, 2006).

Setting plans and goals for action. The present model predicts the need to create specific action plans of established goals. For the technical implementation of the action plan, is considered relevant the use of role 
playing as well as debate with the objective of promoting more appropriate skills and attitudes to each objective (Giglio et al., 1998, Keil et al., 1996; McNally \& Lukens, 2006). It integrates also psychological techniques such as reframing, immersion, visualization and definition of homework (Passmore, 2007). To determine the progress of the development of the model and the success of it, it becomes relevant measures to the assessment of action plan implementation (Kowalski \& Casper, 2007; McNally \& Lukens, 2006; Sherman \& Freas, 2004), the techniques of self-monitoring and the possibility of periodic monitoring interviews with peers, collaborators, and superiors in order to be assessed the degree of progress of the client performance and the objectives to implement (Keil et al.,1996; Saporito, 1996).

Results and effectiveness of the implementation of coaching models. Change and transformation of thought arise when the client raises his self-awareness, which enables him to review its own perceptions and consequently conceive new perceptions as he begins to experience success and see the future with optimism and responsibility (Giglio et al., 1998; Kowalski \& Casper, 2007). The client's personal transformation is also caused by his ability to be more focused and his commitment to change (Giglio et al., 1998; Saporito, 1996; Sherman \& Freas, 2004), as well as the understanding of the consequences of his behavior (Passmore, 2007; Sherman \& Freas, 2004).

Here we can distinguish structural and intrinsic mechanisms of change.

Regarding the structural mechanisms the present model considers that the structure of the coaching process will be a script in which its stages focus behavior change, goal setting and implementation of action plans (Hoojiberg \& Lane, 2009; Keil et al., 1996; Kowalski \& Casper, 2007; McNally \& Lukens, 2006; Sherman \& Freas, 2004), and will also imply providing progress reports of actions taken to the coach (Keil et al., 1996).

Regarding the intrinsic mechanisms considered, it is relevant to note that as the client gets results, it will increase his perception of the return on his investment, which will further motivates his creativity and action (Hoojiberg \& Lane, 2009; Giglio et al., 1998). If the recommendations given in the coaching process are seen as relevant to the context and objectives of the business, they will allow client to adjust his behavior (Saporito, 1996).

In the proposed model is also integrated the perspective of McNally and Lukens (2006), defending the partnership of an external coach with a coach inside the organization, in the development of the coaching process since this combination allows joining greater objectivity with the knowledge of culture and organizational functions. We also believe that it is indispensable the analysis of prior training, experience and certification processes performed by the coach.

It is crucial to ensure that the collaborative work between the coach and the client to encourage and motivate learning will help testing new skills and understand the patterns of relationships between people and the organization (Giglio et al., 1998; Joo, 2005; Keil et al., 1996; Kowalski \& Casper, 2007; McNally \& Lukens, 2006; Passmore, 2007; Saporito, 1996; Sherman \& Freas, 2004). As attributes of the selected coach, diplomacy, the establishment of trust relationships and the ability to moderate conflicts must be present.

Aiming the success of the process, and as a selection criteria for clients, the perspective of is recommended as a criteria for the selection of clients the ability to manage change and accept new challenges, as well as the ability to challenge a more autocratic or vertical ("top down") leadership style (Saporito, 1996). It is also significant the importance that the subordinate assumes to the organization, therefore justifying the cost inherent in the coaching process (Sherman \& Freas, 2004). 


\section{Proposal of an Executive Coaching Model for the Development of an Ethical Leadership Behavior}

This model aims the approach of executive coaching ntervention closest to psychological counseling. The proposed model means to be integrative (Passmore, 2007) and simultaneously uniqueness, by allowing the specificity of skills development for ethical leadership. Although the model suggests a typical pattern, it is malleable, and may allow the coach to move forward sequentially in the stages or re-explore some previously implemented stage, allowing, for example, if he considers necessary, redefining the purpose and plan of action, even being at a more advanced stage of implementation of the coaching process.

This process, defined in seven steps, is dynamic, collaborative, focused on solutions, particularly in the pre-defined goal, focused on the present and oriented to the coachee's ability to act autonomously.

Stage 1: Establishment of a trust relationship between coach and coachee and establishment of the coaching contract. There are two important steps in this phase: building a relationship of trust between coach and coachee and the formalization of the coaching process with the persons involved. The first is related with the relationship with the leader and requires the alignment of expectations, goals and defining the rules and parameters of this relationship (for example, confidentiality, standards of conduct in sessions and others). This first step lays the foundation of the relationship of the executive coaching and development goals of the process (Lankau \& Feldman, 2005).

Prior to verifying the improve in performance, it is needed that the coach builds a close relationship of mutual respect and trust with the coachee in accordance with what is defended in the humanistic perspective. Despite these characteristics proposed by Rogers (1957) being essential but not sufficient (Patterson, 1984), it is essential that the coach believes in the coachee and develops for him an attitude of positive regard. In addition, there is the coach's ability to establish a positive relationship with the coachee, being empathetic and understanding and show concern so that the coachee can find the answers to his problems. It is also necessary openness and honesty in the interaction with the coachee, and the coach should express his feelings when considered important to the coachee and allow him to be able to share their perception without feeling judged.

When the relationship is built, the goal of the coach must consider three aspects: (1) his own emotions and behaviors; (2) the emotions and behavior of the coachee; and (3) managing his emotions and adapt his behavioral responses to achieve a balance between professional detachment and personal intimacy. According to the research by Stein and Book (2000), the higher the management of emotional intelligence of the coach, greater ability to build and maintain effective relationships, so the coach must use the transference and counter-transference of emotions in the relationship so that they can prove useful work.

A second step concerns to the definition of the contract between coach-client-coachee. At this stage, the definition of the parties involved should be present, explicit statements of the confidentiality agreement between coach and client, definition of the contract of the coach or coaches involved (internal coach and the possibility of collaboration with an external coach), rules and standards of conduct in sessions for the coach-coachee partnership and aspects related with schedules, number of sessions and costs.

Stage 2: Leader context analysis and identification of needs and areas of improvement. This step relates to how the coach and coachee may obtain additional information about their own performance. Included in this diagnostic phase is the evaluation of perception by peers, by top management and by subordinates in relation to the coachee, through the application of tools such as the 360-degree assessment (Saporito, 1996; Sherman \& Freas, 2004), questionnaires (Hoojiberg \& Lane, 2009), individual interviews 
(Keil et al., 1996) and the application of ethical leadership scale of Hoog and Hartog (2008) to be filled by the subordinates and in the form of self-report by the leader. Meanwhile, questions may be asked to the leader regarding situations or critical incidents, to better analyze certain issues that are directly related to his difficulties and performance of ethical leadership behavior (Hale \& Whitlmam, 2000). Through questions about the performance, how it was done and the difficulties in implementation, it is possible to identify the individual development needs.

The integration of perspectives from peers, superiors and subordinates in the identification of the problem and in defining the objectives of the data obtained through the leader (coachee), may complete the assessment of leadership style and performance of the leader.

At this stage, the coach helps the coachee to perform a self-assessment by asking about "How I am?", "What I want to be?", "What is happening now?", and "What is the effect or result of this?" (Boyatzis, 2007). This step allows the client (and coach) to understand the results already achieved, skills, behaviors and resources available, beliefs and feelings, while challenging those who limit him (Boyatzis, 2007), and even make possible the review of progress, creating accountability and identifying new learning processes and actions.

Stage 3: Establishment of performance standards and setting goals. The coach, in collaboration with the coachee, begins to identify the phase in which the coachee is on its way for personal change (Miller \& Rollnick, 2002), and helps him to better understand the consequences of his actions and achieve more rational thought patterns around the advantages and disadvantages of their behavior. Therefore, the greater availability of coachee to change will contribute to the higher promotion of reflection and speech regarding the change, with less need for living the problems in the work context. This step allows both to be aware of what they are developing, makes it possible to divide goals into smaller ones and to ensure that all actions are geared towards achieving the goals ("begin with the end in mind") (Covey, 1989 cited by Passmore, 2007). Furthermore, it is important that the definition of the objectives does not conflict with other existing goals and that it is possible to develop a positive and attractive vision of the achievement of goals that encourage action (Passmore, 2007).

After identifying the real needs of development, current performance standards should be identified and established those that the coachee should achieve in the future. At this stage, the coachee's involvement is very important because it is essential to establish his own standards or objectives to a sense of involvement and, consequently, of belonging.

The establishment of these goals should follow the SMART (specific, measurable, achievable, realistic, time-bouded) principles and have to be specific, measurable, attainable, results-focused, and timed.

It is important that the goals are well defined and are in accordance with the development needs of the coachee, before starting to accomplish tasks. Additionally, there must be a realistic proportion between the levels of current performance and those that are intended. When objectives or performance standards are determined, the following phase in the model is action planning.

Stage 4: Action planning for the development of ethical leadership behavior. At this stage, are adopted psychological techniques such as reframing, immersion, visualization and definition of homework (Passmore, 2007).

It is assumed the need of cognitive patterns exploration underlying the visible behaviors, using cognitive-behavioral techniques developed by Beck (1976) and Ellis (1962). For this dimension, it was 
considered also the levels of mentality of the Schein (1985) model adopted in the integrative model of Passmore (2007) and which describes how the individual reads the world and fits his experience in it.

The main goal of the coach is to support the coachee in identifying and challenging his irrational beliefs, associated to ethical leadership, using behavioral techniques, cognitive-emotional and rational therapeutic context as recast, immersion, viewing and suggesting tasks to accomplish at home. In reformulating the perspective of the client, the coach promotes the adoption of a worldview based on rational evidence. Immersion allows precisely the coachee to gradually test this view and immerse himself in a scheme of thought more sustained rationality. Visualization requires the exemplification/simulation of behaviors of the actual context and enhances the validity of the skills developed. The definition of homework to the client, aims to monitoring automatic thoughts and challenge them.

This step is based on the work of Schein (1995) concerning the examination of the culture of the organization and the individual, and which supposes the evaluation of behavior based on five levels (applicable to institutions but also individuals): artifacts, behaviors, mentalities, emotional basis, and motivation. Coach and client should also identify the clear and achievable set of goals (outcomes) for discussion and should question "How to know that this goal was achieved?" and "How to know that the problem was solved?".

Stage 5: Implementation of actions/goals for the implementation of objectives. This stage refers to the relationship between coach and coachee in the implementation of the achievable set of goals (outcomes) about ethical leadership behavior in his context. Coach has to help the coachee to understand the extent and the influence of the system on which he works, both in his behavior and in the behavior of others with whom he interacts.

This step consists in the application of the plans that were previously formulated, which implies that the coachee assumes tasks and responsibilities in order to provide new experiences and learning opportunities.

With regard to leadership and the act of delegating, the greatest difficulty for management positions is the fact they see "their issues"- for which they feel responsible — be solved by other individuals. This situation can lead to a feeling of insecurity by allowing others to take ownership of these projects and responsibilities and the idea that the level of quality will not be assured. This restlessness is partly accepted because the act of delegating is always an element of risk.

The development of the coachee at this stage comes always from an empowering process where he will take responsibility and make decisions without any restrictions. Empowerment is related with the skills and competencies of the coach in applying it (empowering) efficiently and he must take into account the behavior of the coachee (empowered) and affected by the process The correct empowerment is a two-way process in which success is determined by the distinctiveness of the one is applying it (coach) and the characteristics of those who adopt it (coachee) (Hale \& Whitlam, 2000).

The purpose of this phase is that the client can make a list of other possible goals/actions that he can do without judgment and evaluation, and can be encouraged by coach with effective questions (for example, "What else could I do?", "And if this or that constraint were removed?", and "What are the advantages and disadvantages of each option?"). This stage consists in the development of creative thinking of the coachee (Hale \& Whitlam, 2000).

Stage 6: Review of actions and skills transfer. At this stage, coach and coachee present the results of the objectives defined to the client who asked for the coaching process (depending on the initial formalization of the process and the parties involved in it). The intention here is to communicate the result to the client, and to 
facilitate and guide the discussion of the strengths and development areas of the coachee. The coach will also seeks collaboration with other people involved so that they facilitate the influence on the context in which is integrated. Besides that, the coach also has to recognize and explain his influence on the coachee. Thus, according to his system, it is important that the coach works in line with the limits of law and cultural conventions to which his behavior is subjected.

At this stage the coach needs to help the coachee to overcome any resistance to feedback about his ethical leadership behavior and that can be a key representative of the organization. One of the results of this step may be identifying new goals and areas of intervention of the coachee to explore together with the coach.

The main responsibility to the coach is to demonstrate at this stage is his effectiveness in providing a clear and effective feedback, to develop the collaborator and the organization.

It is important to note that the barriers placed to the development and implementation of feedback in organizations is motivated by the fact that the word "feedback", as a rule, has a negative connotation, not only for employees but also to their superiors. Due to this factor, organizations clearly need to implement actions that allow feedback to be a cultural norm.

Stage 7: Assessment of the implementation of the action-evaluation plan of the coaching process. This last step of the proposed coaching model has particular importance for the coachee as a result of the generated feedback of his development throughout the whole process. In this phase, his needs in terms of ethical leadership behavior will be identified, which will lead him to continuous performance improvement.

In each block of two to three sessions an evaluation of the process should be conducted and also has to be predicted an integrative evaluation at the end of the process. The description of the results presented in each phase is dependent on the employment contract between the parties involved: coach—coachee-organization (client).

Once the process ends (after an average of 6-10 sessions), the coach's role is to make an overall assessment of the sessions with the coachee and present the results to other parties involved or other representatives of the organization, as it is initially set on the contracting of the coaching process. In addition, the coach must collect client information in relation to the learning experience and evaluate how coaching helped the organization effectively (Lankau \& Feldman, 2005).

\section{Monitoring Stage of the Actions and Motivations of the Client}

This stage is transverse to the implementation of all other stages of the executive coaching model for the development of ethical leadership. Here we have to search the exploration of unconscious aspects that may exist in each stage as a block to the action (Miller \& Rollnick, 2002).

This stage aims the coachee's awareness of the consequences of his behaviors and the stimulation of his motivation to act, being very useful when there is resistance to change. The use of motivational interviewing in the context of executive coaching is still limited, but may have high potential in these situations (Passmore, 2007).

Below, a graphical representation of the proposed model is shown.

In conclusion, the Executive Coaching Model for Development of Ethical Leadership Behavior is functional because it assumes that is possible to achieve the unconscious level of the coachee and that prevents the coachee from achieving his goal. So, as long as he is in line with his capabilities and goals, setting what behaviors he has to change and the skills to acquire (Passmore, 2007). 


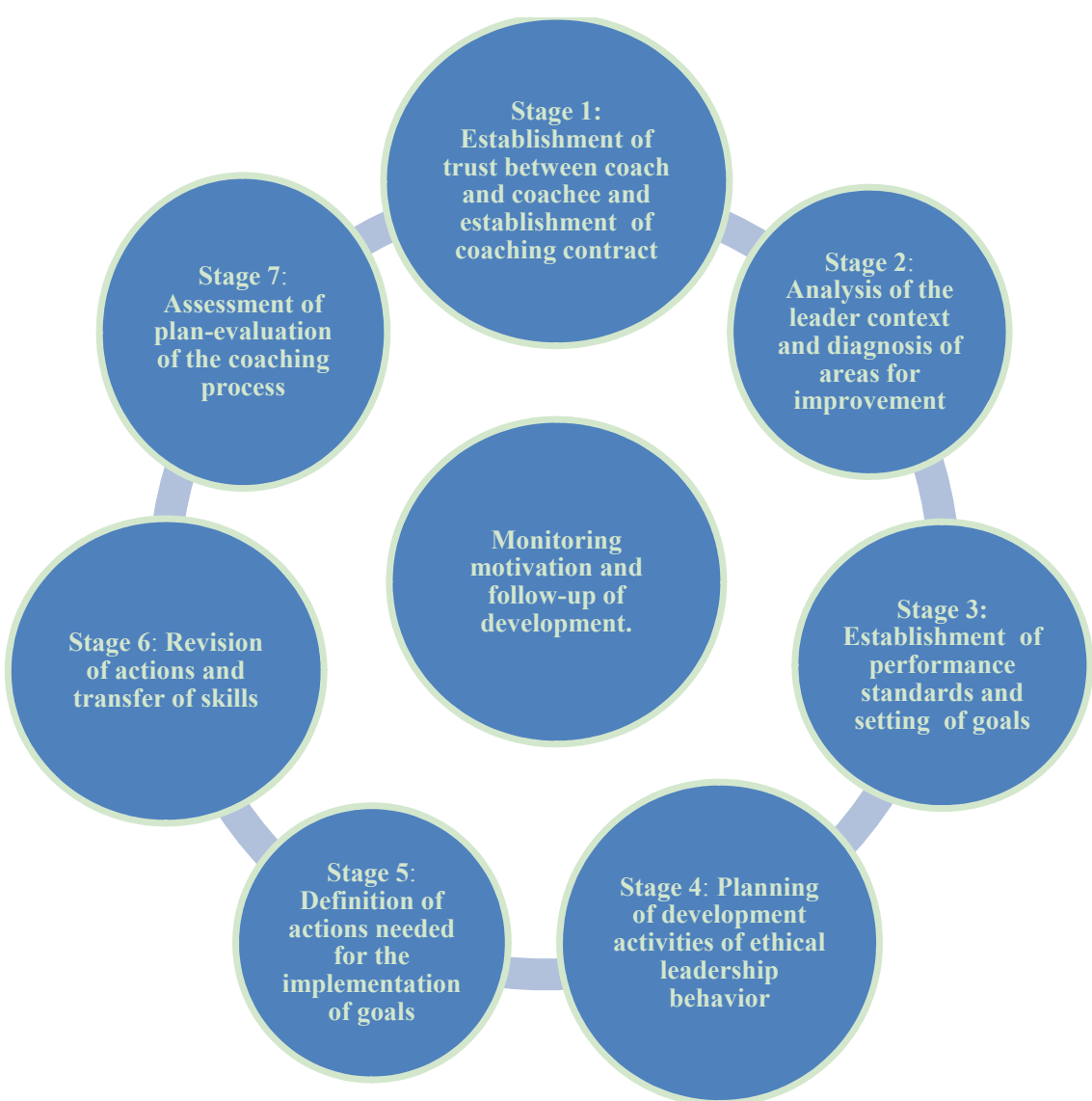

Figure 2. Proposal of an executive coaching model for the development of ethical leadership behavior based on the integrative model by Passmore (2007), on the competence executive coaching model by Koortzen and Oosthuizen.

\section{Conclusion}

The presented model stands out from the coaching approaches proposed by other authors and aims to distinguish itself from approaches similar to consulting and get closer to approaches of psychological counseling and therefore differing in the methods and coaching style used.

The proposed approach emphasizes the process of awareness on the part of the coachee/client (Giglio et al., 1998), oriented towards the definition of a task and organization of the respective action plan (Joo, 2005; Sungkhawan \& Mujtaba, 2009).

Focusing on the client, it is a model directed to the training of leaders for a new role or the development of complementary skills (Joo, 2005; Sungkhawan \& Mujtaba, 2009), such as ethical leadership. Simultaneously, the present model aims the discovery of behaviors and feelings associated with the areas of improvement of the client even if they have to be in a more corrective logic (Passmore, 2007).

The importance of this paper follows the literature review developed about the executive coaching models for the development of ethical leadership and arises in regard of the finding that there has to improved the link between the constructs of executive coaching and the concept of ethical leadership. Moreover, there is a lack of conceptualization of executive coaching models for the development of ethical leadership behavior.

Therefore, it is expected that the conceptual framework and propositions made stimulate more rigorous and relevant research on executive coaching (Passmore, 2007). Finally, there is the need for longitudinal studies 
to support the construction of executive coaching models for the development of ethical leadership and that enhance the evaluation of the effectiveness of the results of executive coaching, so that it does not become transitory like other management practices.

\section{References}

Aronson, E. (2001). Integrating leadership styles and ethical perspectives. Canadian Journal of Administrative Sciences, 18, 244-256.

Ackroyd, S., \& Thompson, P. (1999). Organizational misbehavior. London: Sage.

Ashforth, B. (1994). Petty tyranny in organizations. Human Relations, 47, 755-778.

Augustijnen, M. T., Schnitzer, G., \& Esbroeck, R. V. (2011). A model of executive coaching: A qualitative study. International Coaching Psychology Review, 6(2), 150-164.

Beck, A. T. (1976). Cognitive therapy and the emotional disorders. New York: International Universities Press.

Beckham, D. (2003). Sustainable leadership. Health Forum Journal, 46(3), 43-44.

Bennett, J., \& Bush, M. (2009). Coaching in organizations. OD Practitioner, 41(1), 2-7.

Bennett, K. (2010). Executive coaches' experience of developing their clients' self-coaching capacity. (An abridged version of the project submitted to Middlesex University in partial fulfillment of the requirements for the degree of Masters in Work Based Learning Studies (Professional Coaching), Publication in press).

Bennis, \& Nanus. (1985). The strategies of taking charge. New York: Harper and Row.

Berling, J., Weber, T., \& Kelloway, E. K. (1996). Effects of transformational leadership training on attitudinal and financial outcomes: A field experiment. Journal of Applied Psychology, 81, 827-832.

Bass, B. M., \& Steidlmeier, P. (1999). Ethics, character and authentic transformational leadership behavior. The Leadership Quarterly, 10, 181-218.

Bacon, T. R., \& Spear, K. I. (2003). Adaptive coaching: The art and practice of a client-centered approach to performance improvement. Palo Alto, C.A.: Davis- Black.

Beu, D. S., \& Buckley, M. R. (2004). This is war: How the politically astute achieve crimes of obedience through the use of moral disengagement. The Leadership Quarterly, 15, 551-568.

Bies, R. J. (2000). Interactional (in)justice: The sacred and the profane. In J. Greenberg, \& R. Cropanzano (Eds.), Advances in organizational behavior: Forthcoming Stanford. C.A.: Stanford University Press.

Boyatzis, R. (2007). Developing emotional intelligence through coaching for leadership, professional and occupational excellence. In R. Bar-On, J. Maree, \& M. Elias (Eds.), Educating people to be emotionally intelligent (pp. 155-168). Westport, C.T.: Praeger.

Brown, M. E., \& Treviño, L. K. (2006). Ethical leadership: A review and future directions. Leadership Quarterly, 17, 595-616.

Brown, M. E., Treviño, L. K., \& Harrison, D. (2005). Ethical leadership: A social learning perspective for construct development and testing. Organizational Behavior and Human Decision Processes, 97, 117-134.

Clegg, S. R., Carter, C., Kornberger, M., Messner, M., \& Laske, S. (2007). Business ethics as practice: Representation, discourse and performance. Cheltenham: Edward Elgar.

Clegg, S. R., Kornberger, M., \& Rhodes, C. (2007). Business ethics as practice. British Journal of Management, 18(2), $107-122$.

Cunha, M. P., Marcelino, A. R., Oliveira, C., \& Rêgo, A. (2007). Coaching para executivos. Lisboa: Livraria Escolar Editora.

Ellis, A. (1962). Reason and emotion in psychotherapy. Secaucus, N.J.: Citadel.

Feldman, D. C., \& Lankau, M. J. (2005). Executive coaching: A review and future research agenda. Journal of Management, 31, 829-848.

Freas, A. M. (2000). Coaching executives for business results. In M. L. Goldsmith, \& A. M. Freas (Eds.), Coaching for leadership. San Francisco: Jossey-Bass.

Giglio, L., Diamante, Y., \& Urban, J. (1998). Coaching a leader: Leveraging change at the top. Journal of Management, 17(2), 93-105.

Glynn, M., \& Jamerson, H. (2006). Principled leadership: A framework for action. In E. D. Hess, \& K. S. Cameron (Eds.), Leading values: Positivity, virtue, and high performance (pp. 151-171). Cambridge: Cambridge University Press.

Haas, S. (1992). Coaching: Developing key players. Journal of Nursing Administration, 22(6), 54-58.

Hale, R., \& Whitlam, P. (2000). Powering up performance management. England: Gower. 
Hanges, P. J., \& Dickson, M. W. (2004). The development and validation of the GLOBE culture and leadership scales. In R. J. House, P. J. Hanges, M. Javidan, P. W. Dorfman, \& V. Gupta (Eds.), Culture, leadership, and organizations: The GLOBE study of 62 societies (Vol. 1, pp. 205-218). Thousand Oaks, CA: Sage.

Hartman, S., \& Crow, S. (2002). Executive development in healthcare during times of turbulence. Journal of Management in Medicine, 16(5), 359-370.

Haynor, P. (1994). The coaching, precepting, and mentoring roles of the leader within an organizational setting. Holistic Nurse Practitoner, 9(1), 31-40.

Hoojiberg, R., \& Lane, N. (2009). Using multisource feedback coaching effectively in executive education. Academy of Management Learning \& Education, 8(4), 483-493.

Hoogh, A. H. B., De, \& Hartog, D. N. D. (2008). Ethical and despotic leadership, relationships with leader's social responsibility, top management team effectiveness and subordinates' optimism: A multi-method study. The Leadership Quarterly, 19, 297-311. doi:10.1016/j.leaqua.2008.03.002.

Howell, J. M. (1988). Two faces of charisma: Socialized and personalized leadership in organizations. In J. Conger, \& R. Kanungo (Eds.), Charismatic leadership: The illusive factor in organizational effectiveness (pp. 213-236). San Francisco: Jossey-Bass.

Joo, B. (2005). Executive coaching: A conceptual framework from an integrative review of practice and research. Human Resource Development Review, 4(4), 462-488.

Kampa-Kokesch, S., \& Anderson, M. (2001). Executive coaching: A comprehensive review of the literature. Consulting Psychology Journal: Practice and Research, 53(4), 205-228.

Kanungo, R. N. (2001). Ethical values of transactional and transformational leaders. Canadian Journal of Administrative Sciences, $18,257-265$.

Keil, F., Rimmer, E., Williams, K., \& Doyle, M. (1996). Coaching at the top. Consulting Psychology Journal: Practice and Research, 48(2), 67-77.

Kellerman, B. (2004). Bad leadership. Boston: Harvard Business School Press.

Kilburg, R. (2000).Towards a conceptual understanding and definition of executive coaching. Consulting Psychology Journal: Practice and Research, 48 (2), 134-144. Retrieved from http://web.ebscohost.com/ehost/pdfviewer/pdfviewer?vid=61\&sid= 883b0a59-3139-404c-8853-4b64b15807ab\%40sessionmgr15\&hid=10

Kilburg, R. (2004). When shadows fall: Using psychodynamic approaches in executive

coaching. Consulting Psychology Journal: Practice and Research, 56, 246-268. Retrieved from http://web.ebscohost.com/ehost/pdfviewer/pdfviewer?vid=62\&sid=883b0a59-3139-404c-8853-4b64b15807ab\%40sessionmg r15\&hid=10

Koortzen, P., \& Oosthuizen, R. (2010). A competence executive coaching model. Journal of Industrial Psychology, 121. doi: 10.4102/sajip.v36i1.837

Kotter, J. P., \& Heskett, J. L. (1992). Corporate culture and performance. New York. Free Press.

Kowalski, K., \& Casper. (2007). The coaching process: An effective tool for professional development. Nursing Administration Quarterly, 31(2), 171-179.

Lanciano, T., Curci, A., \& Zatton, E. (2010). Individual differences on mental rumination: The role of emotional intelligence. Europe's Journal of Psychology, 2, 65-84.

McNally, K., \& Lukens, R. (2006). Leadership development: An external-internal coaching process. Journal of Nursing Administration, 36(3), 155-161.

Miller, W. R., \& Rollnick, S. (2002). Motivational interviewing: Preparing people for change (2nd ed.). New York: Guilford Press.

Milner, T., \& Bossers, A. (2004). Evaluation of the mentor-mentee relationship in an occupational therapy mentorship programme. Occupational Therapy International, 11(2), 96-111.

Mujtaba, B., \& Sungkhawan, J. (2009). Situational leadership and diversity management coaching skills. Journal of Diversity Management, 4(1), 1-12.

Neves, L., Jordão, F., \& Cunha, M. P. (2014a). Executive coaching for the development of leadership skills: A literature review. International Journal of Evidence Based Coaching and Mentoring (in Press).

Neves, L., Jordão, F., \& Cunha, M. P. (2014b). Estudo de adaptação e validação de uma Escala de Liderança Ética à População Portuguesa. In Revista Ibero-Americana de Psicologia. Universidade do Porto: Publicação em prelo.

Passmore, J. (2007). An integrative model for executive coaching. Consulting Psychology Journal: Practice and Research, 59(1), 68-78. 
Patterson, C. H. (1984). Empathy, warmth and genuineness in psychotherapy: A review of reviews. Psychotherapy, 21, 431-438.

Performance Coaching International. (2006). Retrieved from http://www.performancecoachinginternational.com/resources/ articles/historyofcoaching.asp

Price, A. (2009). Using coaching interventions to develop clinical skills. Nursing Standard, 23(44), 48-55.

Rogers, C. (1957). The necessary and sufficient conditions of therapeutic personality change. Journal of Consulting Psychology, 21, 95-103.

Rost, \& Smith. (2003). Leadership. Kogan Page Publishers. 195 páginas.

Saporito, T. (1996). Business-linked executive development: Coaching senior executives. Consulting Psychology Journal: Practice and Research, 48(2), 96-103.

Sampaio, A. (2004). Comportamento e cultura organizacional. Lisboa, Ediual.

Schein, E. H. (1985). Organizational culture and leadership. San Francisco: Jossey-Bass.

Sherman, S., \& Freas, A. (2004). The Wild West of executive coaching. Harvard Business Review, 82(11), 82-90, 148.

Stein, S., \& Book, H. (2000). The EQ edge: Emotional intelligence and your success. Toronto: MHS.

Tepper, B. J. (2000). Consequences of abusive supervision. Academy of Management Journal, 43, 178-191.

Trevino, L. K., Brown, M., \& Hartman, L. P. (2003). A qualitative investigation of perceived executive ethical leadership: Perceptions from inside and outside the executive suite. Human Relations, 56, 5-37.

Truijen, K., \& Woerkom, M. (2008). The pitfalls of collegial coaching. Journal of Workplace Learning, 29(5), 316-326.

Whitmore, J. (2002). Coaching for performance: Growing people, performance and purpose. London: Nicholas Brealey Publishing.

Wasylyshyn, K., Gronsky, B., \& Haas, J. W. (2006). Tigers, stripes, and behavior change: Survey results of a commissioned coaching program. Consulting Psychology Journal: Practice and Research, 58(2), 65-81. 